\title{
DNAzyme Hybridization, Cleavage, Degradation and Sensing in Undiluted Human Blood Serum
}

\author{
Wenhu Zhou ${ }^{1,2}$, Qingyun Chen², Po-Jung Jimmy Huang ${ }^{2}$, Jinsong Ding ${ }^{1, *}$ and Juewen Liu ${ }^{1,2, *}$ \\ 1. School of Pharmaceutical Sciences, Central South University, Changsha, Hunan, China, \\ 410013. \\ Email: dingjs0221@163.com \\ 2. Department of Chemistry, Waterloo Institute for Nanotechnology, University of Waterloo, \\ Waterloo, Ontario, Canada, N2L 3G1. \\ *Email: liujw@uwaterloo.ca
}

This document is the Accepted Manuscript version of a Published Work that appeared in final form in Analytical Chemistry, copyright @ American Chemical Society after peer review and technical editing by publisher. To access the final edited and published work see http://dx.doi.org/10.1021/ acs.analchem.5b00220. 


\begin{abstract}
RNA-cleaving DNAzymes provide a unique platform for developing biosensors. However, a majority of the work has been performed in clean buffer solutions, while the activity of some important DNAzymes in biological sample matrices is still under debate. Two RNA-cleaving DNAzymes (17E and 10-23) are the most widely used. In this work, we carefully studied a few key aspects of the 17E DNAzyme in human blood serum, including hybridization, cleavage activity and degradation kinetics. Since direct fluorescence monitoring is difficult due to the opacity of serum, denaturing and non-denaturing gel electrophoresis were combined for studying the interaction between serum proteins and DNAzymes. The 17E DNAzyme retains its activity in $90 \%$ human blood serum with a cleavage rate of $0.04 \mathrm{~min}^{-1}$, which is similar to that in the PBS buffer $\left(0.06 \mathrm{~min}^{-1}\right)$ with a similar ionic strength. The activity in serum can be accelerated to 0.3 $\min ^{-1}$ with an additional $10 \mathrm{mM} \mathrm{Ca}^{2+}$. As compared to $17 \mathrm{E}$, the $10-23$ DNAzyme produces negligible cleavage in serum. Degradation of both the substrate and the DNAzyme strand is very slow in serum, especially at room temperature. Degradation occurs mainly at the fluorophore label (linked to DNA via an amide bond) instead of the DNA phosphodiester bonds. Serum proteins can bind more tightly to the 17E DNAzyme complex than to the single-stranded substrate or enzyme. The 17E DNAzyme hybridizes extremely fast in serum. With these understandings, detection of DNA using the 17E DNAzyme is demonstrated in serum.
\end{abstract}




\section{Introduction}

Developing functional DNA based analytical tools has recently become a key topic in bioanalytical chemistry. ${ }^{1-6}$ DNAzymes are DNA-based catalysts, representing an important class of functional DNA. DNAzymes have been widely used because of their excellent activity, programmability, signal amplification through catalytic turnovers, and stability. ${ }^{6-9}$ The analytical application of DNAzymes can be classified based on target analytes. Some DNAzymes are active only in the presence of certain metal ions, and are used for metal sensing. ${ }^{10-16}$ Other types of analytes (including nucleic acids, small molecule metabolites and proteins) can be detected using the aptazyme technology, where an aptamer is coupled to modulate DNAzyme activity. ${ }^{17}$

Most analytical applications of DNAzymes have been demonstrated in clean buffer solutions, while applications in biological sample matrices such as serum or cells are less explored. ${ }^{18-23}$ On a parallel research front, RNA-cleaving DNAzymes are used for intracellular mRNA cleavage in antiviral and anticancer applications. ${ }^{24}$ So far, these studies were performed by measuring only the final outcome (e.g., mRNA or protein suppression) without following the reaction steps. Results from different assays are sometimes inconsistent, and it is often difficult to identify a reason for such inconsistency. For example, concerns have been raised regarding DNAzyme activity in the presence of physiological concentrations of $\mathrm{Mg}^{2+} \cdot 25-27$

An important aspect of expanding the analytical application of DNAzymes is to involve biological sample matrices. ${ }^{28}$ For example, a common perception is that free DNA might be quickly degraded by nucleases in biological fluids, keeping many researchers away from related studies. ${ }^{29}$ To move forward, a few important reaction steps need to be studied, including DNAzyme degradation, binding to proteins, hybridization kinetics, and finally, DNAzyme cleavage activity. Only once all 
of these aspects are fully understood, can one confidently use DNAzymes for in vitro or in vivo sensing.

We reason that serum is a suitable starting point for a systematic understanding of biological sample matrices. ${ }^{30,31}$ Serum is readily available in large quantities compared to mammalian cell extracts. The overall chemical composition of serum is comparable to the intracellular environment in terms of ionic strength and protein concentration (Table S1), although the species of metal ions and proteins is quite different.

For the purpose of RNA cleavage, two DNAzymes have been studied extensively. ${ }^{32}$ The $10-23$ DNAzyme was reported to have excellent activity for RNA cleavage, while the 8-17 (or 17E) DNAzyme has been researched more as a model for $\mathrm{Pb}^{2+}$ detection. ${ }^{10,33}$ Both enzymes have excellent substrate generality and they cleave both full RNA and RNA/DNA chimeric substrates. ${ }^{32}$,

34 The 17E DNAzyme is a well-characterized system, ${ }^{35-38}$ and various methods have been developed to engineer it into biosensors. ${ }^{1,13,16,33,39}$ In this work, we aim to study 17E in undiluted human blood serum. A brief comparison with the 10-23 DNAzyme is also made. Our results support the activity and analytical applications of $17 \mathrm{E}$ in such a complex matrix.

\section{Materials and Methods}

Chemicals. All of the DNA samples were purchased from Eurofins (Huntsville, AL). See Table 1 for sequences. The metal salts were from Sigma-Aldrich. Sodium phosphate, 2-(N-morpholino) ethanesulfonic acid (MES) free acid monohydrate, 4-(2-hydroxyethyl) piperazine-1ethanesulfonate (HEPES), EDTA disodium salt dihydrate, and sodium chloride were from Mandel Scientific (Guelph, Ontario, Canada). Sodium dihydrogen phosphate dihydrate, and disodium 
orthophosphate heptahydrate were from Fisher Scientific. Gel loading dye (6x) was from New England Biolabs. Human AB serum was from Mediatech (Manassas, VA, USA). TBE buffer (10x) and urea were from Biobasic (Markham, ON, Canada). All buffers and solutions were prepared with Milli-Q water.

DNAzyme stability assay. The stability assays were performed with a final concentration of $90 \%$ serum and $0.5 \mu \mathrm{M}$ labeled DNA. DNA was dissolved and diluted in $5 \mathrm{mM}$ HEPES (pH 7.6). At designated time points, $1 \mu \mathrm{L}$ of $5 \mu \mathrm{M}$ FAM-labeled substrate or Cy5-labeled enzyme was mixed with serum. After incubation, a quenching solution containing $8 \mathrm{M}$ urea and $1 \times$ gel loading dye was added. The degradation products were separated on a $15 \%$ denaturing polyacrylamide gel and analyzed using a ChemiDoc MP imaging system (Bio-Rad).

Serum protein binding assay. Gel-based protein binding assays were performed with a final concentration of $0.5 \mu \mathrm{M}$ inactive DNAzyme complex $\left(\left[3^{\prime} \mathrm{FAM}-\mathrm{sub}\right]=0.5 \mu \mathrm{M},[17 \mathrm{Ec}]=1 \mu \mathrm{M}\right)$. This complex was annealed in MES buffer (50 mM, pH 6.0, $25 \mathrm{mM} \mathrm{NaCl})$. Human blood serum of different concentrations was diluted with $10 \mathrm{mM}$ PBS buffer (pH7.5, $1 \mathrm{mM} \mathrm{Mg}^{2+}, 2.5 \mathrm{mM} \mathrm{Ca}^{2+}$, $150 \mathrm{mM} \mathrm{NaCl}$ ). $1 \mu \mathrm{L}$ of the complex was added to various concentrations of serum and incubated for $20 \mathrm{~min}$. The products were analyzed using non-denaturing (no urea added) or denaturing (containing $8 \mathrm{M}$ urea) polyacrylamide gel. For protein binding kinetics, $1 \mu \mathrm{L}$ substrate $(5 \mu \mathrm{M})$ and $1 \mu \mathrm{L} 17 \mathrm{E}(10 \mu \mathrm{M})$ were separately added to $8 \mu \mathrm{L}$ serum. At designated time points, the quenching solution was added, followed by gel electrophoresis analysis.

Activity assays. For a typical gel-based activity assay, $1 \mu \mathrm{L}$ DNAzyme ([3'FAM-sub] $=5 \mu \mathrm{M}$, $[17 \mathrm{E}]=10 \mu \mathrm{M})$ complex was added to $9 \mu \mathrm{L}$ serum or PBS to initiate the reaction. At designated 
time points, samples were quenched with $8 \mathrm{M}$ urea containing $20 \mathrm{mM}$ EDTA and separated using $15 \%$ denaturing polyacrylamide gel for analysis.

DNA detection in serum. Prior to the assay, $3^{\prime}$ FAM-sub, 17E-F1 and 17E-F2 were mixed at a ratio of $1: 1: 1$, and then diluted by serum with a final substrate concentration of $2.5 \mu \mathrm{M}$. The target DNA and mismatch DNA were diluted to various concentrations with serum. Then $1 \mu \mathrm{L}$ of each of the abovementioned solutions were added to $7 \mu \mathrm{L}$ serum, and $1 \mu \mathrm{L}$ of $500 \mathrm{mM} \mathrm{Ca}^{2+}$ was added to accelerate the reaction. After $1 \mathrm{~h}$ incubation, the reaction was stopped by adding $10 \mu \mathrm{L}$ quenching solution (8 M urea containing $20 \mathrm{mM}$ EDTA) for gel-based analysis.

Table 1. DNA oligonucleotides used in this study.

\begin{tabular}{ll}
\hline DNA Name & Sequence and modifications (from 5'-terminus) \\
\hline 3'FAM-sub & GTCACGAGTCACTATrAGGAAGATGGCGAAA-FAM \\
5'FAM-sub & FAM-GTCACGAGTCACTATrAGGAAGATGGCGAAA \\
17E & TTTCGCCATCTTCTCCGAGCCGGTCGAAATAGTGACTCGTGAC \\
17E-Cy5 & TTTCGCCATCTTCTCCGAGCCGGTCGAAATAGTGACTCGTGAC-Cy5 \\
17Ec & TTTCGCCATCTTCCCCGAGCCGGTCGAAATAGTGACTCGTGAC \\
17E-F1 & GCTGGTCATCCAGCAGCGGTCGAAATAGTGACTCGTGAC \\
17E-F2 & TTTCGCCATCTTCTCCGAGCGTGTTCGACAATGGC \\
10-23 & GGTATCATCTTGAGGCTAGCTACAACGAGGTCAGACCGTCA \\
10-23-sub & TGACGGTCTGACCrATCAAGATGATACC \\
Target DNA & GCCATTGTCGAACACCTGCTGGATGACCAGC \\
Mis-match & GCCTTTGTCGAATTTTTTTTTGGATTTCCAGC \\
\hline
\end{tabular}




\section{Results and Discussion}

Sample matrix considerations. Serum represents a very complex sample matrix for analytical chemistry. The activity of the 17E DNAzymes is strongly affected by $\mathrm{pH}$ and divalent metal ions. ${ }^{32}$, ${ }^{35,40}$ However, these parameters are fixed in serum. The main chemical composition of serum is shown in Table S1. While additional metal salts can be added for analytical assays, adjusting $\mathrm{pH}$ appears to be less practical, especially for a small sample volume. For in vivo RNA cleavage applications, the physiological condition has to be used. Therefore, we performed most of our studies in the original serum without dilution or doping.

Serum contains a higher concentration of $\mathrm{Ca}^{2+}$ than of $\mathrm{Mg}^{2+}$ (Table S1), and the 17E DNAzyme is more active with $\mathrm{Ca}^{2+}{ }^{41}$ This also favors our studying 17E. The opacity of serum precludes the direct use of common fluorophore labels for in situ monitoring. ${ }^{42,43}$ Instead, gel electrophoresis was employed, and the coefficient of variation (CV) is below $10 \%$ for most of our measurements.

A

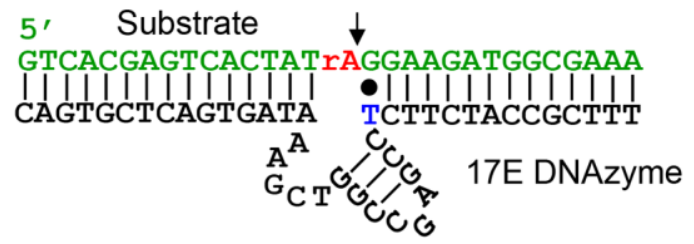

C

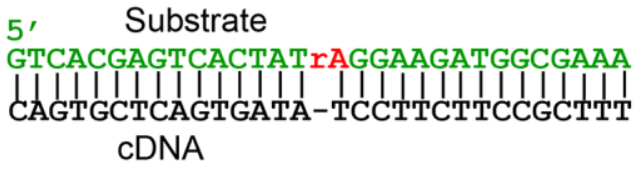

B
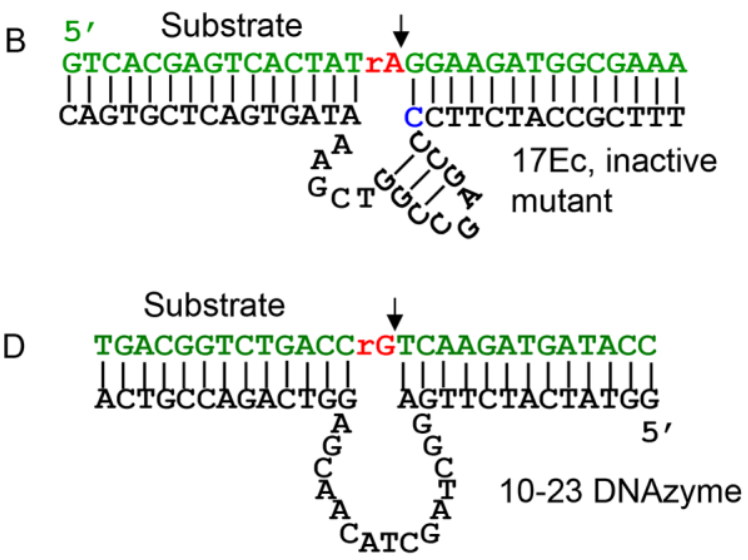

Figure 1. The secondary structures of (A) the 17E DNAzyme, (B) the inactive mutant 17Ec with a $T$ base replaced by a $C$ (in blue), (C) the substrate forming a duplex with the cDNA, and (D) the 10-23 DNAzyme. The arrowheads point at the cleavage site. 
DNAzyme stability in serum. Since nuclease-induced DNA degradation is a major concern, we first tested DNAzyme stability in serum. The 17E DNAzyme complex is comprised of a substrate and an enzyme strand (Figure 1A). The enzyme is a pure DNA chain and the substrate is a RNA/DNA chimera with a single RNA base (rA) at the cleavage site. 17E cleaves both full RNA and the chimeric substrate with similar activity. ${ }^{32}$ The substrate strand was studied first. To track degradation, its $3^{\prime}$-end was labeled with a FAM (carboxyfluorescein, 3'FAM-sub in Table 1). At $22{ }^{\circ} \mathrm{C}$ (i.e. room temperature), the substrate is quite stable in serum (90\%), degrading only $~ 5 \%$ in $2 \mathrm{~h}$ (Figure $2 \mathrm{~A}, \mathrm{D}$ ). However, at $37^{\circ} \mathrm{C}$ (i.e. body temperature), degradation is much faster, reaching $\sim 30 \%$ in $2 \mathrm{~h}$. A control experiment in PBS buffer shows no degradation at $37^{\circ} \mathrm{C}$ (Figure 2D, green dots, and Figure S1). We reason that degradation at higher temperatures might be due to protein enzymes in serum, which are more active at $37^{\circ} \mathrm{C}$.

The degradation pattern does not indicate cleavage at the RNA nucleotide position, which is a weak linkage susceptible for cleavage. ${ }^{44}$ This is concluded by comparing the degradation pattern to the RNA cleavage product after base treatment (the last lane of Figure 2A). Most degradation occurs near the FAM label, since the darkest degradation band corresponds to a very short piece of DNA or even the fluorophore alone. Therefore, this single RNA base does not seem to compromise the stability of the substrate in concentrated serum. 

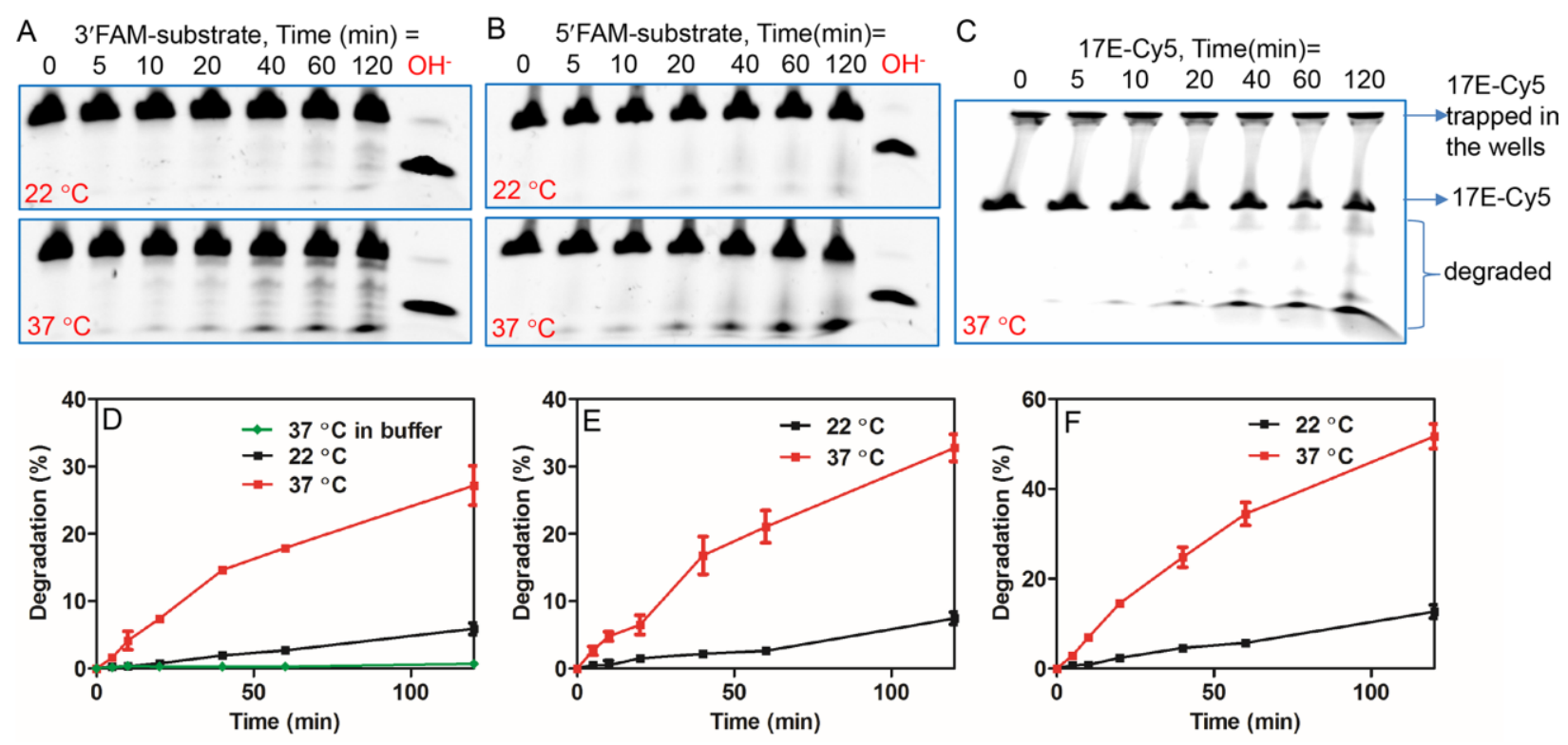

Figure 2. Gel-based stability assay (A-C) and quantification (D-F) at $22{ }^{\circ} \mathrm{C}$ and $37{ }^{\circ} \mathrm{C}$ for degradation kinetics in 90\% human blood serum of 3'FAM-sub (A, D), 5'FAM-sub (B, E), and 17E-Cy5 (C,F). See Table 1 for DNA sequence. The $\mathrm{OH}^{-}$treated lanes represent the product of cleavage at the RNA base (rA) position. In (C), three bands are observed in each lane and the top bands are DNA trapped in the well without migration.

To confirm the effect of the FAM label, we also measured the same substrate bearing a 5'-FAM (5'FAM-sub). Interestingly, the same degradation pattern is observed (Figure 2B, E), further supporting that degradation occurs at the FAM label and the substrate itself is quite stable. Finally, the enzyme strand was tested with a Cy5 label (Figure 2C, F). It has slightly faster degradation kinetics compared to the substrate, and degradation also occurs near the Cy5 label. Therefore, the phosphodiester bonds in DNA are quite stable in serum (much more stable than that reflected from the degradation profile). Serum contains nucleases, but their activity is affected by DNA binding to proteins, ${ }^{45}$ which may contribute to the high DNA stability we observed. The fluorophores are 
linked to DNA via amide bonds, which appear to be cleaved more easily in serum, possibly due to proteases in serum. ${ }^{46}$ We noticed that a fraction of the enzyme stands were retained in the wells of the gel without migration, indicating its complex formation with serum proteins. Overall, the DNAzyme is stable in serum for hours, which should be sufficient for most analytical work at room temperature. For long-term in vivo RNA cleavage, however, degradation needs to be reduced, which might be achieved via conjugation to nanomaterials, ${ }^{29}$ or using modified DNA. ${ }^{47}$

Binding to serum proteins. The protein concentration in serum is quite high $(60-80 \mathrm{~g} / \mathrm{L}),{ }^{48}$ creating a crowded environment. In addition, proteins may bind the DNAzyme and affect its activity. Therefore, serum binding to DNAzyme was studied next. A few DNA complexes were prepared for this study (Figure 1A-C), and they were analyzed by both non-denaturing and denaturing gel electrophoresis.

Figure 3A shows the non-denaturing gel. Lane 1 is the free $3^{\prime}$ FAM-sub in PBS buffer; lane 2 is the same substrate in serum, for which no migration occurs. Therefore, serum proteins can completely sequester the substrate strand under the non-denaturing condition. ${ }^{49}$ On the other hand, under denaturing conditions (denatured by $8 \mathrm{M}$ urea, Figure 3B), all the substrate is released and migrates at the same speed as that in the PBS buffer. Since urea disturbs hydrogen bonds, hydrogen bonding appears to be important for the substrate-protein binding. Both types of gels contain EDTA, which chelates divalent metal ions and thus metal mediated interactions can be ruled out. To further confirm the binding mechanism, we then used urea alone or EDTA alone to treat the mixture before running a non-denaturing gel. The substrate was bound in the EDTA sample, but was free in the urea treated sample (Figure S2), supporting the critical role of hydrogen bonding. We further studied the effect of base composition, and a 15 -mer poly-G DNA is fully retained by 
serum even in the denaturing condition, while the other three DNA homopolymers are dissociated (Figure S3). Therefore, guanine is largely responsible for the binding interaction. ${ }^{49-51}$

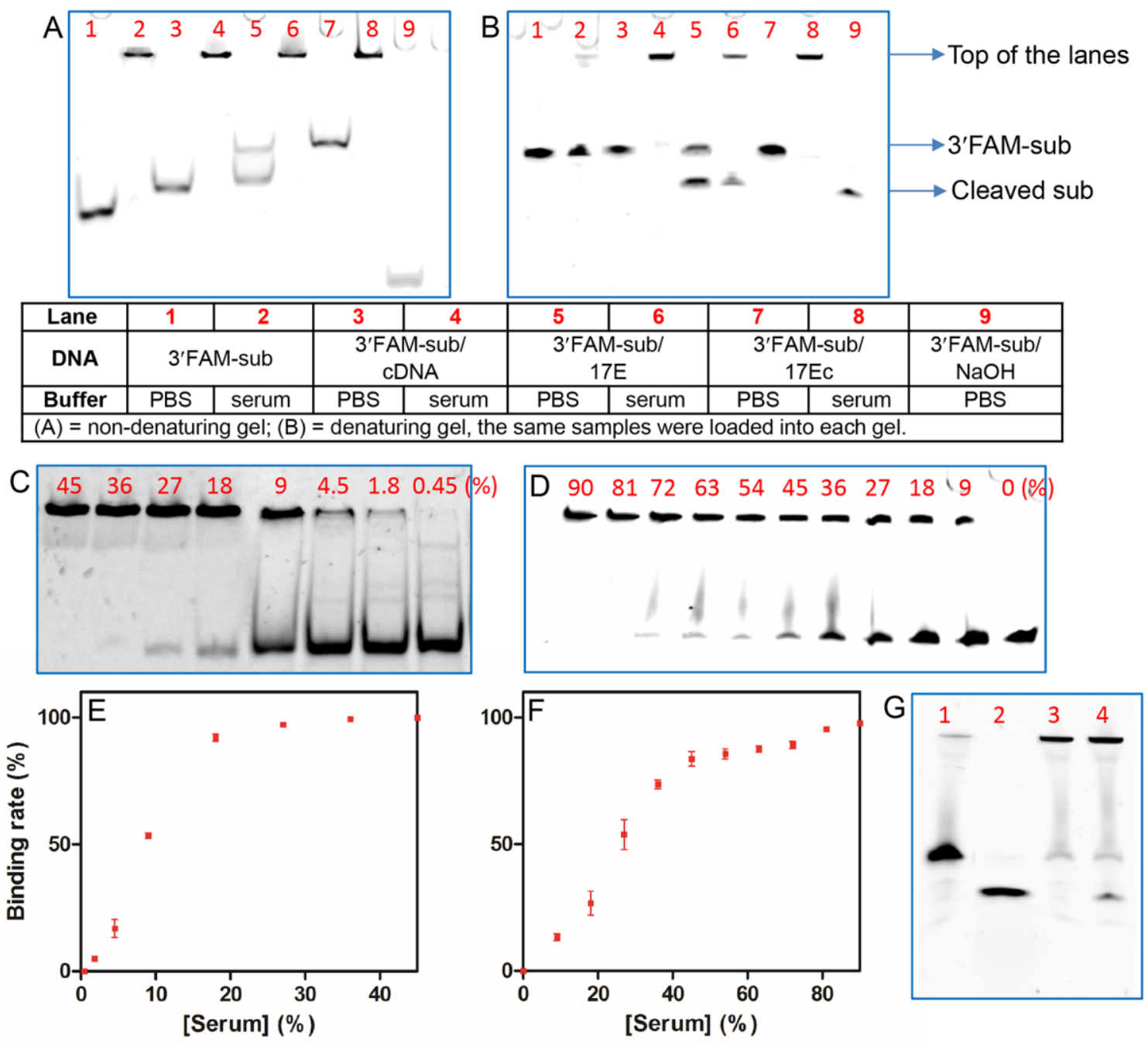

Figure 3. (A) Non-denaturing and (B) denaturing gel electrophoresis analysis of serum binding to the DNAzyme and control complexes. The composition of each lane is described in the table. (C) Non-denaturing and (D) denaturing gel of the inactive DNAzyme (3'FAM-sub/17Ec) binding to different concentrations of serum. Quantification of the DNAzyme binding for (E) non-denaturing and (F) denaturing conditions. (G) Gel image for studying DNAzyme hybridization in serum using denaturing gel. Lane 1: 3'FAM-sub in serum; lane 2: 3'FAM-sub treated with $\mathrm{NaOH}$; lane 3 and 
4: mixing 3'FAM-sub with $17 \mathrm{E}$ in serum for $2 \mathrm{sec}$ and $2 \mathrm{~min}$, respectively, before gel electrophoresis.

Lane 3 is the full duplex consisting of the substrate and its cDNA in PBS buffer. Since it has a higher molecular weight, it migrates slightly slower than the free substrate in lane 1 of Figure $3 \mathrm{~A}$. In the denaturing gel (Figure 3B), this duplex is denatured and the substrate migrates the same as the free substrate. Lane 4 is the same duplex but in serum, and it is fully retained in both gels. Therefore, the duplex is maintained in serum even under the denaturing condition. Otherwise, the denatured single-stranded substrate should migrate as in lane 2 of Figure 3B. We can also conclude that the binding of the DNA duplex to the serum proteins is more stable compared to the binding of the single-stranded substrate alone under denaturing conditions.

By searching the literature, a number of serum proteins were identified for specific DNA binding, such as DNA-binding protein 1 and 2. The amount of DNA binding proteins occupies $\sim 1.5 \%$ of the total serum proteins. ${ }^{51}$ While these proteins can bind both single- and double-stranded DNA, ${ }^{50}$ the duplex binding is less affected by urea based on our results.

Lane 5 is the 17E DNAzyme complex in buffer, where cleavage occurred as expected, producing a shorter segment of DNA. Lane 6 is the DNAzyme complex in serum, and full retention was observed in the non-denaturing gel, similar to that in lane 4. The denaturing gel indicates that the DNAzyme is still active in serum: a fraction of the substrate was cleaved, and the rest was retained in the well. Therefore, even though the DNAzyme contains a large bulge, it still behaves like a duplex and can be tightly bound by serum proteins. Lanes 7 and 8 are the mutated inactive DNAzyme 17Ec complex (Figure 1B) in buffer and serum, respectively. In both cases, no cleavage 
occurred, confirming the specific cleavage in lane 6 . The last lanes are the $\mathrm{NaOH}$ treated substrate, showing the position of the cleavage product. These experiments indicate that serum proteins bind more strongly to the DNAzyme complex than to the single-stranded substrate.

To quantify binding affinity, we used the inactive 17Ec DNAzyme (Figure 1B) to construct a binding curve. This complex was incubated with various concentrations of serum and denaturing gel was used for analysis (Figure 3C). More binding was observed with increasing serum concentration. From the binding curve (Figure 3E), the middle point is $9 \%$ serum. Next, we quantified binding under denaturing conditions (Figure 3D), and a similar pattern was observed, although the middle point is at $\sim 25 \%$ serum (Figure $3 F$ ). The DNA-binding proteins occupy $\sim 1.5 \%$ of the serum protein mass, and the molecular weight of such proteins is around $100,000 .^{50,51} \mathrm{We}$ estimated the molar concentration of DNA binding proteins to be $\sim 10 \mu \mathrm{M}$ in undiluted serum, assuming total serum protein is $70 \mathrm{~g} / \mathrm{L}$. If all the DNAs were bound by these proteins, the $K_{\mathrm{d}}$ 's under non-denaturing and denaturing conditions are 0.9 and $2.5 \mu \mathrm{M}$, respectively. This affinity is comparable with previously reported for long duplex DNA. ${ }^{52}$ Taken together, concentrated serum proteins can bind the DNAzyme complex but such binding does not inhibit the DNAzyme activity.

DNA hybridization kinetics. In a typical DNAzyme assay, the substrate and enzyme strands are pre-annealed to form the complex, which can be activated by adding divalent metal ions. In some applications, however, the enzyme strand needs to be added separately (e.g. for cleaving viral RNA), and DNAzyme hybridization is important in this case. We next studied the hybridization reaction. For this purpose, we need to separate the free substrate from the DNAzyme complex. Since in non-denaturing gel, the free substrate is associated with serum (e.g. lane 2 of Figure 3A), denaturing gel electrophoresis was employed. 
The first lane (Figure 3G) is the substrate alone in serum, which migrates normally under denaturing conditions. Lane 2 is the $\mathrm{NaOH}$ treated sample showing the position of the cleaved substrate. Lanes 3 and 4 are the substrate and enzyme mixed in serum for $\sim 2$ sec and 2 min, respectively. Interestingly, hybridization was complete even after $2 \mathrm{sec}$ (otherwise, the nonhybridized free substrate should appear). Therefore, concentrated serum proteins do not impede DNAzyme hybridization. In fact, the crowded serum environment may even assist hybridization due to the macromolecular crowding effect. ${ }^{53-55}$

Activity in serum. Even though serum proteins bind the DNAzyme, very fast hybridization can still occur and we also observed cleavage in some assays. To gain a quantitative understanding of DNAzyme activity, cleavage kinetics was measured. A typical gel is shown in Figure 4A, where time-dependent cleavage is observed in $90 \%$ serum. The cleavage rate is $0.04 \mathrm{~min}^{-1}$ (Figure 4C, red dots). When EDTA was added as a control, no cleavage was observed. Serum has a fixed pH and metal composition with a total $\mathrm{Ca}^{2+}$ and $\mathrm{Mg}^{2+}$ concentration being $\sim 3.6 \mathrm{mM}$ (Table S1). A similar rate $\left(0.06 \mathrm{~min}^{-1}\right)$ was observed in PBS containing a similar divalent metal concentration $\left(\mathrm{Ca}^{2+}=2.5 \mathrm{mM}\right.$ and $\mathrm{Mg}^{2+}=1 \mathrm{mM}$, Figure $4 \mathrm{C}$, black dots $)$. When an additional $10 \mathrm{mM}$ of $\mathrm{Ca}^{2+}$ was used, the rate reached $\sim 0.3 \mathrm{~min}^{-1}$ (Figure 4D, black dots). Therefore, the reaction rate is largely determined by the metal concentration. With $10 \mu \mathrm{M} \mathrm{Pb}^{2+}$ in buffer (no serum), the rate is estimated to be greater than $10 \mathrm{~min}^{-1}$ which is too fast to measure by manual pipetting (Figure $4 \mathrm{D}$, green dots). However, $\mathrm{Pb}^{2+}$ was not added to serum because of its toxicity and it might be sequestered by serum proteins. ${ }^{56} \mathrm{We}$ did not observe enhanced rate with additional $\mathrm{Pb}^{2+}$ or $\mathrm{Zn}^{2+}$ in serum (Figure S4). At physiological temperature of $37^{\circ} \mathrm{C}$, the DNAzyme is also slightly faster (Figure S5). Overall, the physiological concentration of serum metal ions is useful for supporting the activity of the 17E DNAzyme. 

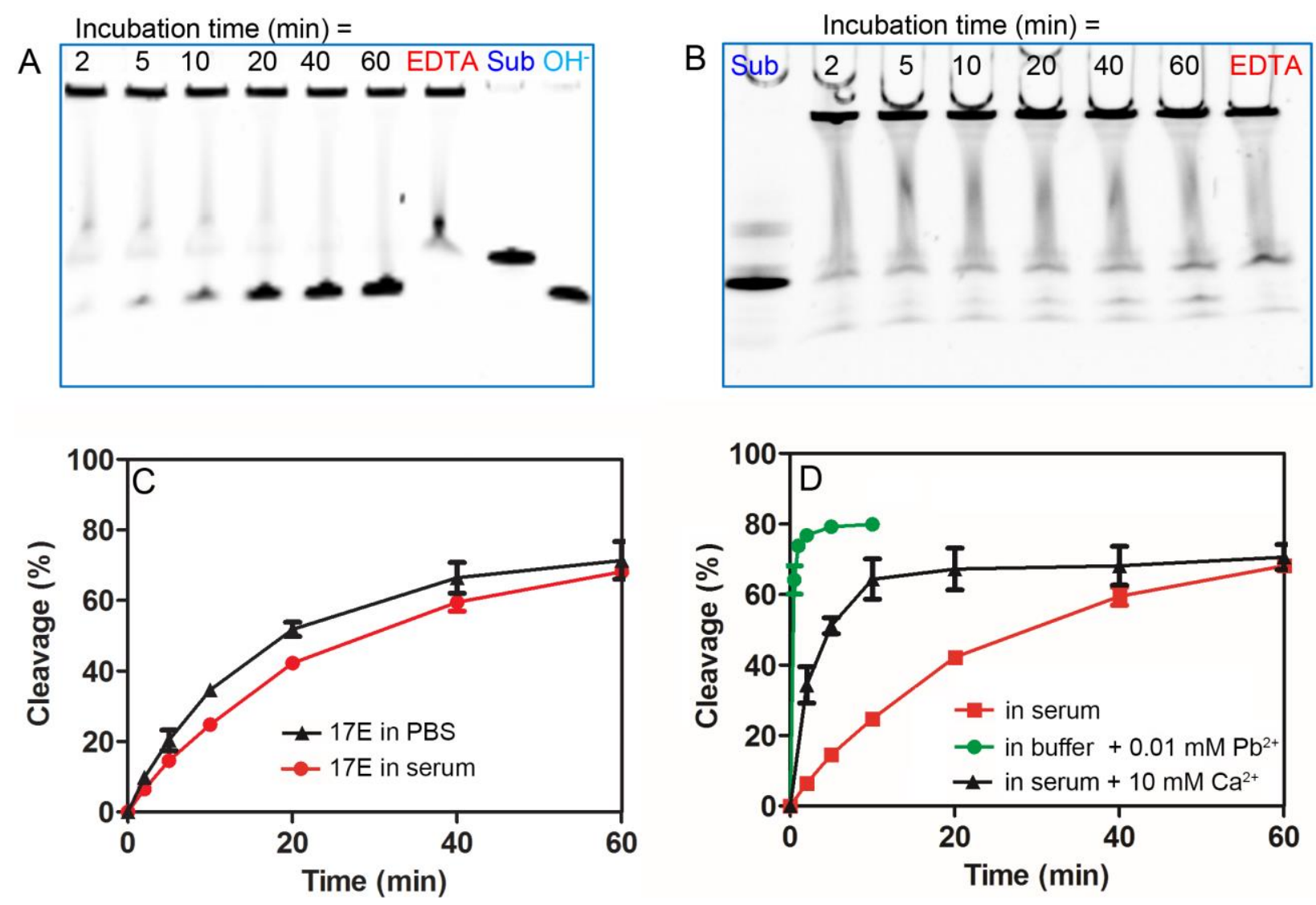

Figure 4. Gel images for activity of (A) the 17E DNAzyme and (B) the 10-23 DNAzymes in $90 \%$ serum. (C) Activity of $17 \mathrm{E}$ in PBS and $90 \%$ serum. (D) Activity of $17 \mathrm{E}$ in $10 \mu \mathrm{M} \mathrm{Pb}^{2+}$ in $50 \mathrm{mM}$ of MES buffer ( $\mathrm{pH} 6.2$ ), in $90 \%$ serum and serum with additional $10 \mathrm{mM} \mathrm{Ca}^{2+}$.

To date, most RNA cleavage work was carried out with the 10-23 DNAzyme. ${ }^{24}$ This might be related to the initial biochemical characterization of this enzyme. ${ }^{32}$ For comparison, we also measured the cleavage of the 10-23 DNAzyme in serum (see Figure 1D for structure), and found that it barely cleaved any substrate (Figure 4B). Similar observations were also made in buffer (Figure S6). This supports the concern that RNA cleavage by the 10-23 DNAzyme in biological buffer conditions is hindered due to a lack of metal ions. ${ }^{25,26,57}$ On the other hand, the $17 \mathrm{E}$ DNAzyme is reasonably active in serum, making 17E a better choice for use in biological systems. 
A
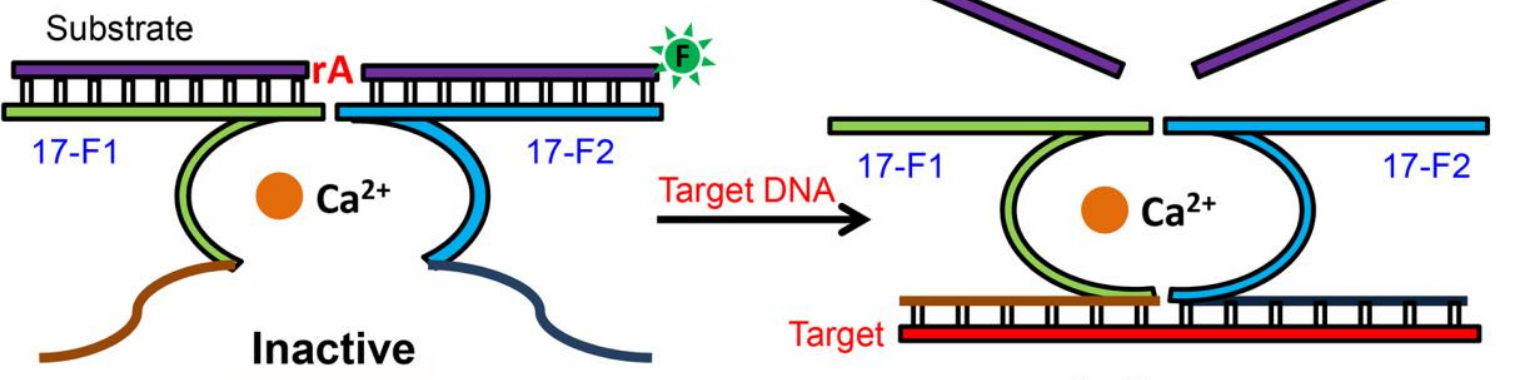

Active
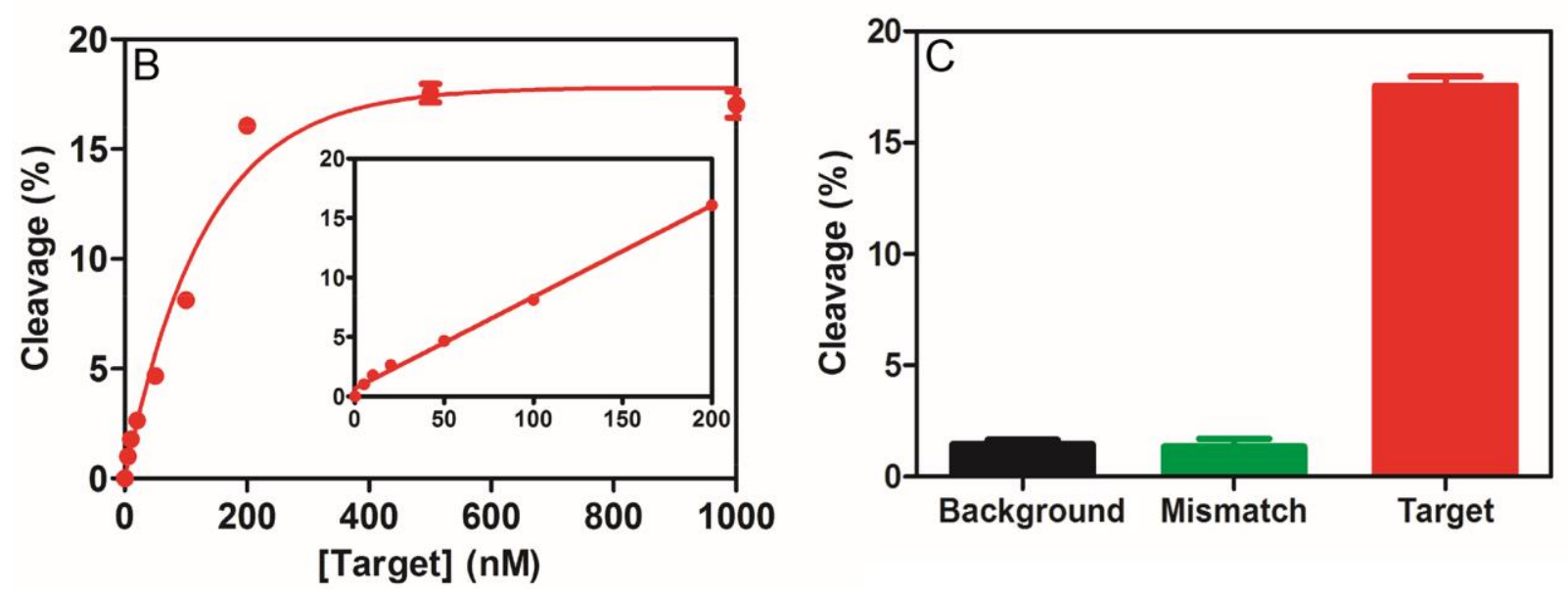

Figure 5. (A) Scheme of MNAzyme-based DNA detection. (B) Cleavage of the substrate strand as function of the target DNA concentration. (C) Specificity test with a non-target DNA.

Detecting DNA in serum. An important application of DNAzymes is metal detection. While such applications have been demonstrated for intracellular metal detection, ${ }^{18-22}$ detection of non-metal targets is also important. After understanding various aspects of the DNAzyme in serum, we aimed to test its application for DNA detection. The main goal of this work is to study the sample matrix effect instead of designing new sensing strategies. Therefore, the previously reported MNAzyme technology was used. ${ }^{58}$ The enzyme strand was split into two halves and extended, which abolished 
its activity (Figure 5A). Activity is achieved only in the presence of a target strand that can assemble the two enzyme halves. Indeed, we observed target concentration dependent cleavage in serum, with a detection limit of $6 \mathrm{nM}$ (Figure 5B). The sensitivity can be improved by incorporation of other signaling methods such as lanthanide luminescence, ${ }^{43}$ gold nanoparticles or polymerase enzymes. ${ }^{59} \mathrm{We}$ also observed high specificity; if a non-target DNA was added, no cleavage occurred (Figure 5C). Therefore, DNAzyme-based assays can still occur in undiluted serum.

\section{Conclusions}

In summary, we employed the 17E DNAzyme as a model system to study a few important steps of DNAzyme reaction in undiluted human blood serum. In general, DNA oligonucleotides and DNAzymes are tightly associated with concentrated serum proteins even under denaturing conditions. Degradation of the DNAzyme in serum is moderate and takes place at the fluorophore label instead of in the DNA backbone. Hybridization of the DNAzyme complex in serum is very fast and the activity of the 17E DNAzyme in serum is similar to the activity of that in PBS buffer with similar divalent metal ion concentrations. A faster reaction rate can be achieved by adding

$\mathrm{Ca}^{2+}$ above the normal level in serum. Detection of DNA in serum is demonstrated based on the MNAzyme method. This work may stimulate new analytical opportunities for the DNAzyme community to develop biosensors in biological sample matrices. 


\section{Acknowledgement}

This work is supported by the University of Waterloo, the Natural Sciences and Engineering Research Council of Canada (NSERC), Foundation for Shenghua Scholar of Central South University and the National Natural Science Foundation of China (Grant No. 21301195). Wenhu Zhou is supported by the Fellowship from the China Scholarship Council (CSC, Grant No. 201406370116).

Supporting Information Available. Metal ion composition in serum, addition temperature and metal dependent activity and control experiments. This information is available free of charge via the Internet at http://pubs.acs.org/.

\section{References}

(1) Liu, J.; Cao, Z.; Lu, Y. Chem. Rev. 2009, 109, 1948-1998.

(2) Tan, W. H.; Donovan, M. J.; Jiang, J. H. Chem. Rev. 2013, 113, 2842-2862.

(3) Rosi, N. L.; Mirkin, C. A. Chem. Rev. 2005, 105, 1547-1562.

(4) Li, D.; Song, S. P.; Fan, C. H. Acc. Chem. Res. 2010, 43, 631-641.

(5) Katz, E.; Willner, I. Angew. Chem., Int. Ed. 2004, 43, 6042-6108.

(6) Famulok, M.; Hartig, J. S.; Mayer, G. Chem. Rev. 2007, 107, 3715-3743.

(7) Zhang, X.-B.; Wang, Z.; Xing, H.; Xiang, Y.; Lu, Y. Anal. Chem. 2010, 82, 5005-5011.

(8) Silverman, S. K. Acc. Chem. Res. 2009, 42, 1521-1531.

(9) Schlosser, K.; Li, Y. F. Chem. Biol. 2009, 16, 311-322.

(10) Zhang, X.-B.; Kong, R.-M.; Lu, Y. Annu. Rev. Anal. Chem. 2011, 4, 105-128.

(11) Liu, J.; Brown, A. K.; Meng, X.; Cropek, D. M.; Istok, J. D.; Watson, D. B.; Lu, Y. Proc. Natl. Acad. Sci. U.S.A. 2007, 104, 2056-2061.

(12) Liu, Z.; Mei, S. H. J.; Brennan, J. D.; Li, Y. J. Am. Chem. Soc. 2003, 125, 7539-7545.

(13) Wang, H.; Kim, Y.; Liu, H.; Zhu, Z.; Bamrungsap, S.; Tan, W. J. Am. Chem. Soc. 2009, $131,8221-8226$. 
(14) Hollenstein, M.; Hipolito, C.; Lam, C.; Dietrich, D.; Perrin, D. M. Angew. Chem., Int. Ed. 2008, 47, 4346 - 4350.

(15) Huang, P.-J. J.; Lin, J.; Cao, J.; Vazin, M.; Liu, J. Anal. Chem. 2014, 86, 1816-1821.

(16) Xiao, Y.; Rowe, A. A.; Plaxco, K. W. J. Am. Chem. Soc. 2007, 129, 262.

(17) Cho, E. J.; Lee, J.-W.; Ellington, A. D. Annu. Rev. Anal. Chem. 2009, 2, 241-264.

(18) Wu, P.; Hwang, K.; Lan, T.; Lu, Y. J. Am. Chem. Soc. 2013, 135, 5254-5257.

(19) Hwang, K.; Wu, P.; Kim, T.; Lei, L.; Tian, S.; Wang, Y.; Lu, Y. Angew. Chem., Int. Ed. 2014, 53, 13798-13802.

(20) Gao, X. Y.; Huang, H. M.; Niu, S. Y.; Ye, H. Z.; Lin, Z. Y.; Qiu, B.; Chen, G. N. Anal. Methods 2012, 4, 947-952.

(21) Kim, S.; Ryoo, S.-R.; Na, H.-K.; Kim, Y.-K.; Choi, B.-S.; Lee, Y.; Kim, D.-E.; Min, D.-H. Chem. Commun. 2013, 49, 8241-8243.

(22) Zhang, L.; Huang, H.; Xu, N.; Yin, Q. J. Mater. Chem. B 2014, 2, 4935-4942.

(23) Fan, H.; Zhao, Z.; Yan, G.; Zhang, X.; Yang, C.; Meng, H.; Chen, Z.; Liu, H.; Tan, W. Angew. Chem., Int. Ed. 2015, DOI: 10.1002/anie.201411417.

(24) Baum, D. A.; Silverman, S. K. Cell. Mol. Life Sci. 2008, 65, 2156-2174.

(25) Young, D. D.; Lively, M. O.; Deiters, A. J. Am. Chem. Soc. 2010, 132, 6183-6193.

(26) Hollenstein, M.; Hipolito, C. J.; Lam, C. H.; Perrin, D. M. ACS Comb. Sci. 2013, 15, 174182.

(27) Cieslak, M.; Szymanski, J.; Adamiak, R. W.; Cierniewski, C. S. J. Biol. Chem. 2003, 278, 47987-47996.

(28) Hajslova, J.; Zrostlikova, J. J. Chromatogr. A 2003, 1000, 181-197.

(29) Seferos, D. S.; Prigodich, A. E.; Giljohann, D. A.; Patel, P. C.; Mirkin, C. A. Nano Lett. 2009, 9, 308-311.

(30) Ashby, J.; Flack, K.; Jimenez, L. A.; Duan, Y.; Khatib, A.-K.; Somlo, G.; Wang, S. E.; Cui, X.; Zhong, W. Anal. Chem. 2014, 86, 9343-9349.

(31) Zhou, W.; Jimmy Huang, P.-J.; Ding, J.; Liu, J. Analyst 2014.

(32) Santoro, S. W.; Joyce, G. F. Proc. Natl. Acad. Sci. U.S.A. 1997, 94, 4262-4266.

(33) Li, J.; Lu, Y. J. Am. Chem. Soc. 2000, 122, 10466-10467.

(34) Schlosser, K.; Gu, J.; Sule, L.; Li, Y. F. Nucleic Acids Res. 2008, 36, 1472-1481.

(35) Brown, A. K.; Li, J.; Pavot, C. M. B.; Lu, Y. Biochemistry 2003, 42, 7152-7161. 
(36) Schlosser, K.; Li, Y. ChemBioChem 2010, 11, 866-879.

(37) Wang, B.; Cao, L.; Chiuman, W.; Li, Y.; Xi, Z. Biochemistry 2010, 49, 7553-7562.

(38) Peracchi, A.; Bonaccio, M.; Clerici, M. J. Mol. Biol. 2005, 352, 783-794.

(39) Liu, J. W.; Lu, Y. J. Am. Chem. Soc. 2003, 125, 6642-6643.

(40) Santoro, S. W.; Joyce, G. F. Biochemistry 1998, 37, 13330-13342.

(41) Faulhammer, D.; Famulok, M. Angew. Chem., Int. Ed. 1996, 35, 2837-2841.

(42) Huang, P. J. J.; Liu, J. W. Anal. Chem. 2010, 82, 4020-4026.

(43) Li, L.-L.; Ge, P.; Selvin, P. R.; Lu, Y. Anal. Chem. 2012, 84, 7852-7856.

(44) Li, Y.; Breaker, R. R. J. Am. Chem. Soc. 1999, 121, 5364-5372.

(45) Napirei, M.; Ludwig, S.; Mezrhab, J.; Klöckl, T.; Mannherz, H. G. FEBS J 2009, 276, 1059-1073.

(46) Dekker, L. J. M.; Burgers, P. C.; Charif, H.; van Rijswijk, A. L. C. T.; Titulaer, M. K.; Jenster, G.; Bischoff, R.; Bangma, C. H.; Luider, T. M. Proteomics 2010, 10, 2348-2358.

(47) Deleavey, Glen F.; Damha, M. J. Chem. Biol. 2012, 19, 937-954.

(48) Greger, R.; Windhorst, U., Eds. Comprehensive Human Physiology; Springer-Verlag: Berlin-Heidelberg, 1996.

(49) Chinen, A. B.; Guan, C. M.; Mirkin, C. A. Angew. Chem., Int. Ed. 2014, 54, 527-531.

(50) Gardner, W. D.; Hoch, S. O. J. Biol. Chem. 1979, 254, 5238-5242.

(51) Sylvia, P.; Brehm, S. O.; Hoch, H. J. A. Biochem. Biophys. Res. Comm. 1975, 63, 24-31.

(52) Richmond, T. J.; Steitz, T. A. J. Mol. Biol. 1976, 103, 25-38.

(53) Miyoshi, D.; Sugimoto, N. Biochimie 2008, 90, 1040-1051.

(54) Paudel, B. P.; Rueda, D. J. Am. Chem. Soc. 2014, 136, 16700-16703.

(55) Dupuis, N. F.; Holmstrom, E. D.; Nesbitt, D. J. Proc. Natl. Acad. Sci. U.S.A. 2014, 111, 8464-8469.

(56) Magyar, J. S.; Weng, T.-C.; Stern, C. M.; Dye, D. F.; Rous, B. W.; Payne, J. C.; Bridgewater, B. M.; Mijovilovich, A.; Parkin, G.; Zaleski, J. M.; Penner-Hahn, J. E.; Godwin, H. A. J. Am. Chem. Soc. 2005, 127, 9495-9505.

(57) Wang, F.; Saran, R.; Liu, J. Bioorg. Med. Chem. Lett. 2015. DOI: http://dx.doi.org/ 10.1016/j.bmcl.2015.02.032.

(58) Mokany, E.; Bone, S. M.; Young, P. E.; Doan, T. B.; Todd, A. V. J. Am. Chem. Soc. 2009, 132, 1051-1059. 
(59) Liu, Z.; Liu, B.; Ding, J.; Liu, J. Anal. Bioanal. Chem. 2014, 406, 6885-6902. 